\title{
SELF-EXPANDABLE NITINOL STENT PLACEMENT IN HOMOCYSTEINEMIC PORCINE AORTA
}

\author{
Luís Henrique Gil França, Adamastor Humberto Pereira, Sílvio César Perini
}

França LHG, Pereira AH, Perini SC. Self-expandable nitinol stent placement in homocysteinemic porcine aorta. Clinics. 2008;63:229-36.

PURPOSE: To compare aortic intimal thickening of normal and hyperhomocysteinemic pigs (induced with a methionine-rich diet) following placement of a self-expanding nitinol stent.

METHODS: Eighteen Macau pigs were used. They were older than eight weeks in age and had an average weight of $30 \mathrm{~kg}$. Pigs were randomly divided into two groups. The first, Group C (control), was fed a regular diet, and the second group, Group M, was fed a methionine-rich diet for 30 days to induce hyperhomocysteinemia. The self-expandable nitinol stents were $25 \mathrm{~mm}$ in length and $8 \mathrm{~mm}$ in diameter after expansion. Blood samples were collected to measure total cholesterol, triglycerides, HDL and homocysteine concentrations. All animals were subjected to angiography. Thirty days after the procedure, the animals were sacrificed, and the abdominal aorta was removed for histological and digital morphometry analysis.

RESULTS: Under microscopic evaluation, the intima was significantly thicker in Group C than in Group M. When groups were compared by digital morphometric analysis, intimal thickening of the vessel wall was higher in Group C than in Group M. There was no significant change in total cholesterol, triglycerides or HDL concentrations in either group. In group $\mathrm{C}$ the levels of plasma homocysteine ranged from 14,40 to $16,73 \mu \mathrm{mol} / 1$; in Group M, plasma homocysteine levels ranged from 17.47 to $59.80 \mu \mathrm{mol} / 1$ after 30 days of a methionine-rich diet.

CONCLUSION: Compared to normal pigs, less intimal hyperplasia was observed in the abdominal aortas of hyperhomocysteinemic pigs thirty days after the insertion of a self-expandable nitinol stent.

KEYWORDS: Homocysteine. Artery. Intimal hyperplasia. Animal models.

\section{INTRODUCTION}

Treating peripheral vascular disease with endovascular procedures is a rapidly expanding field in the medical practice. Percutaneous transluminal angioplasty (PTA) reduces luminal stenosis by breaking plaques and expanding the disease-free portion of the arterial wall. The corresponding injury involves endothelial exposure and intimomedial tears. ${ }^{1}$ Although balloon angioplasty provides good results, both acutely and chronically, stents are being more frequently used to improve patency. ${ }^{2,3}$

Department of Surgery, Vascular Surgery Section, Universidade Federal do Rio Grande do Sul, Hospital de Clínicas de Porto Alegre - Porto Alegre/ RS, Brazil.

luishgf@hotmail.com

Received for publication on 29/08/07

Accepted for publication on 14/11/07
Since the placement of the first intravascular stent in 1985 by Palmaz, stenting has become an effective procedure to treat large-caliber vessel stenosis. ${ }^{2}$ However; stenting is still considered a controversial procedure. While stenting is considered acceptable for aortoiliac vessels, it is still questionable for the femoropopliteal or more distal vasculature. ${ }^{3}$ In recent years, nitinol has become the preferred metal alloy for making stents because of its thermoreactive shape-memory characteristics, ${ }^{3}$ which provide both flexibility and self-expandability.

Restenosis of treated vessels is one of the causes of clinical symptom recurrence after revascularization, and it is a common limitation of endovascular procedures, with a restenosis recurrence rate of $30-40 \%$ within three to six months. Acute restenosis is often the result of wall spasm, in situ thrombosis, or elastic recoil. Intimal hyperplasia is an important key factor in chronic restenosis ${ }^{1,4}$ and promotes in-stent restenosis. In contrast to atherosclerosis, smooth 
muscle cell migration and intimal proliferation are critical early events in intimal hyperplasia. The main process (proliferation and migration) is completed in pigs after 28 days, while in humans cellular proliferation reaches its maximum by three to six months without further progression. ${ }^{1,11,12}$ The neointima is similar to that observed in humans with respect to cell size, cell density, and histological presentation. ${ }^{2,4,12}$

Important atherosclerosis risk factors were described in the Framingham study and have been further expanded and elucidated. ${ }^{5}$ These risk factors include hyperlipidemia, hypertension, and diabetes, along with epidemiologic factors such as smoking, diet, stress and family history. ${ }^{5,6}$ The theory that homocysteine could contribute to atherosclerosis was first proposed by McCully \& Wilson in $1975 .{ }^{18}$ In addition to favoring atheromatous plaque formation in elastic and muscular arteries, it can also cause both arterial and venous thrombosis, affecting vessels of any diameter. It is still uncertain whether normalizing or lowering plasma homocysteine levels impacts the incidence and development of vascular diseases. ${ }^{19}$ In fact, high homocysteine levels causes peripheral arterial disease. ${ }^{7}$ Patients with hyperhomocysteinemia have pre-existing intimal hyperplasia in saphenous vein biopsies, an increasing rate of vein graft stenosis and increased bypass graft failure. ${ }^{8}$ Hyperhomocysteinemia may also be associated with accelerated disease progression. ${ }^{8,9}$ However, the effects of hyperhomocysteinemia on endovascular procedures are unknown.

Research in endovascular surgery is constantly evolving. Early studies focused on the morphology, physiology, and pathogenesis of reactions occurring after stent placement. Experimenting with more suitable animal models has been a constant goal and motive of much debate. ${ }^{2,11}$ In humans, endovascular procedures are performed in atherosclerotic arteries with large amounts of plaque, while the same procedures are used to create injuries in normal, disease-free vessels in animal models in most experiments. As a result, the contributing factors of restenosis may be different, which would explain why many therapeutic strategies in clinical trials fail. ${ }^{2,11}$ Swine and primates best meet the requirements of a restenosis model and develop lesions that are physiologically and morphologically similar to humans. ${ }^{11}$ We hypothesize that intimal hyperplasia in homocysteinemic pigs arteries may be greater than in normal pigs after stent deployment. The purpose of this study was to evaluate and compare aortic intimal thickening of normal and hyperhomocysteinemic pigs using digital morphometry after the placement of selfexpanding nitinol stents.

\section{MATERIAL AND METHODS}

The study was approved by the Ethical Committee for the Post Graduation Group at Hospital de Clínicas de Porto
Alegre, Brazil. The experiment was conducted in the Research Center facilities of the referred hospital. Nitinol stents were manufactured by the Mechanical Transformation Lab of the Engineering School of the Federal University of Rio Grande do Sul (Laboratório de Transformação Mecânica da Escola de Engenharia da Universidade Federal do Rio Grande do Sul) based on ELLA-CS ${ }^{\circledR}$, Dr. Varel Volenec's stent patterns. Those stents were self-expandable, $25 \mathrm{~mm}$ in length and $8 \mathrm{~mm}$ in expanded diameter, ethylene-oxide cleansed, and sterilized.

Eighteen Macau pigs were used in the study, all over eight weeks of age with an average weight of $30 \mathrm{~kg}$. Pigs were randomized into two groups. Each group was kept separately and labeled as Group C (control group) and Group M (methionine group). Pigs in group $\mathrm{C}$ were given standard pig chow and drinking water ad libitum. Pigs in group $\mathrm{M}$ were fed the same chow plus 3\% methionine for 30 days before the day of surgery; methionine supplementation was then discontinued. The aim of this study was to promote arterial lesions prior to the endovascular procedure. Animal models are difficult to obtain because they require long maintenance periods of hyperlipemic diets administered to specific genetic breeds. ${ }^{11,12}$ To avoid such problems and promote early atherosclerosis in pigs, we used a 30-day methionine-rich diet to promote arterial lesions. These lesions were similar to those previously described by Rolland et al, ${ }^{13}$ and we have previously shown that a 30-day methionine-rich diet consistently promotes homocysteine arterial lesions in pig iliac arteries ${ }^{21}$ and rabbit aortas..$^{20}$

Blood samples were collected at day 0, 30 and 60 to determine total cholesterol, triglycerides, HDL, and homocysteine concentrations. Total cholesterol, triglycerides and HDL analyses were performed by enzymatic-colorimetric methods. Homocysteine was determined by HPLC (high performance liquid chromatography). Homocysteine levels were measured at the onset of the methionine supplementation (30 days prior to surgery), on the day of surgery, and 30 days after surgery.

Exclusion criteria included animal death before the time established for tissue collection, surgical complications during or after surgery, and technical failures of tissue preparation or processing.

\section{Surgical procedures}

The surgical procedure was performed at 30 days. Anesthesia was induced by an intramuscular injection of xylazine. Prior to endotracheal intubation, anesthesia was increased by intravenous ketamine injection, which was followed by orotracheal intubation and volume-controlled ventilation using $1.5 \%$ isoflurane. No oral anticoagulant or antiplatelet therapy 
was used in the follow-up period to facilitate neointimal formation. Postoperative pain management included intramuscular administration of Tramal (tramadol) and Dipirona (dipyrone). Antibiotic prophylaxis with IV cefazolin was administered on the day of surgery. After sterile preparation, the carotid artery was dissected through an oblique cervical incision, and a 7F sheath and 0.035 stiff guidewire were introduced. All animals received IV heparin (5000U) after the carotid sheaths were inserted. The stents were then deployed at the infra-renal abdominal aorta. After stent placement, angiography was performed, the carotid access site was ligated, and the surgical wound was closed with resorbable sutures. Thirty days after the procedure, follow-up angiography and animal sacrifice was performed (at 60 day), and the abdominal aorta segment was removed for histological and digital morphometry analysis.

\section{Histological analysis}

The infra-renal portion of the aorta was removed and irrigated with a $0.9 \%$ sodium chloride solution, and vessel patency was checked macroscopically. Specimens were cut longitudinally in the segment containing the stent, and transverse sections were obtained. All sections were fixed in $10 \%$ formaldehyde. Transverse sections from the stent's mid-part were removed for morphometric analysis. Segments were processed, set in paraffin blocks and later sectioned at $4 \mu \mathrm{m}$ for display on the microscope slides. Slides were then prepared and stained with hematoxylin and eosin.

\section{Morphometric analysis}

Quantification methodology was employed to determine intimal thickening of the stents using digital morphometric analysis based on an integrated morphometric program and image analysis (Media Cybernetics: Image Pro Plus). Histological sections were digitalized for morphometric analysis by conventional optical microscopy (Zeiss Microscope, Axiastar Model), achromatic optical plane and photo-storage tube (Sony® DXC 151 Video Camera), which generated image files in a PC. Images were digitalized with a 100-magnification microscope, and the intimal and medial areas were delimited, respectively, for the internal elastic membrane and endothelium. Area dimensions were described in $\mathrm{mm}^{2}$, using the average of eight microscopic fields. The external and internal elastic membranes defined the medial area, while the area limited by the internal elastic membrane and the endothelium was considered the intimal area. The pathologist was blinded to the group in which each animal belonged. Results were expressed as the median (interquartile range, IQR). Mann-Whitney's and Friedman's tests were used for statistical analysis between groups. Significance level was set at $p<0.05$.

\section{RESULTS}

Eighteen animals were initially included in the study. All except four recovered fully between procedures. Two died of myocardial ischemia, one died from carotid artery rupture during the procedure, and the last animal was sacrificed because of paraplegia secondary to an occluded stent 24 hours after deployment. These four animals were excluded from the study. All stents placed in the remaining fourteen animals were patent immediately after deployment and remained this way until the follow-up angiography was performed (Figure 1). All animals remained clinically healthy until sacrifice.

Macroscopic evaluation of abdominal aorta specimens demonstrated that the stents were firmly attached to the aortic wall and covered by a thin, translucent cover in Group M (Figure 2). In Group C, the aortic wall was extensively covered on the luminal surface (Figure 3). Extensive intimal
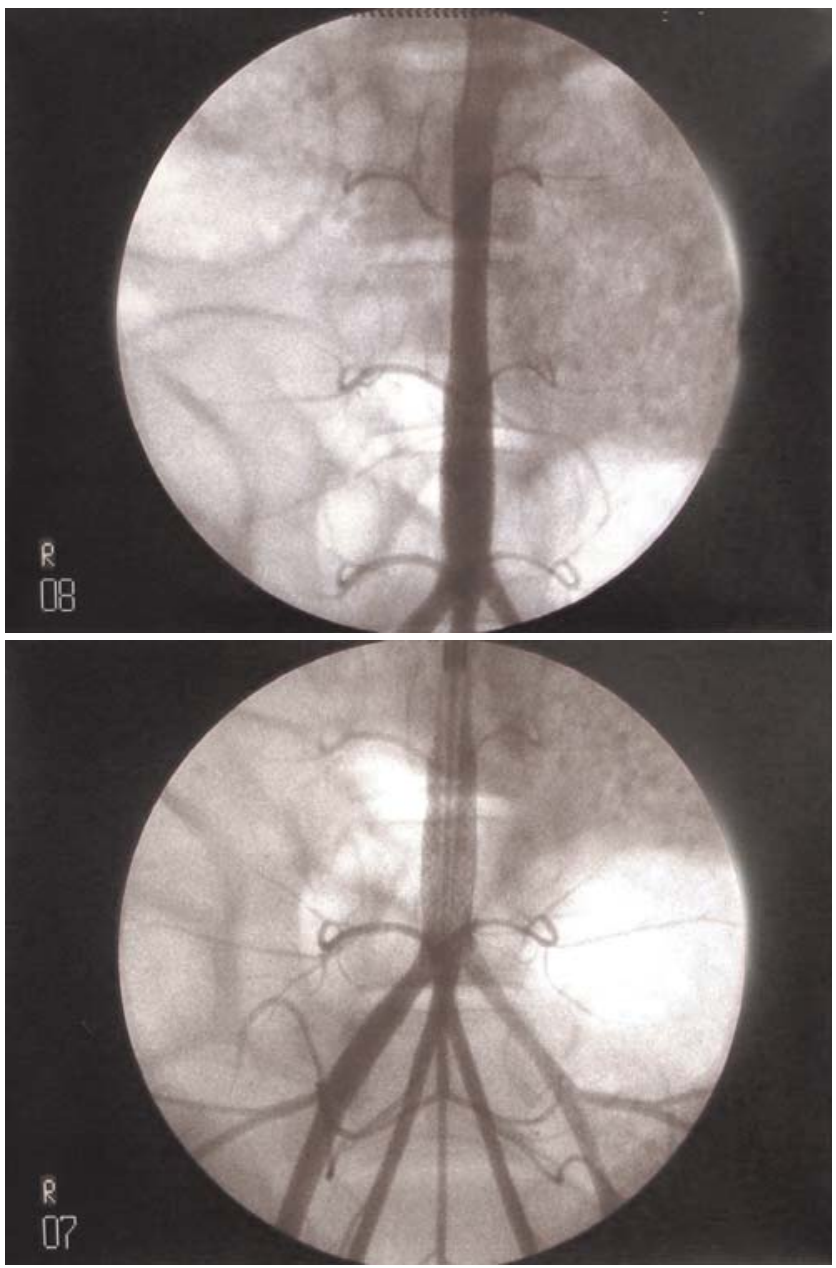

Figure 1 - Angiography after stent deployment in pig aorta 
hyperplasia with no endothelial deposits and a well-defined internal elastic lamina was observed upon histological evaluation of the aortas in Group C (Figure 4). The abdominal aorta in Group $\mathrm{M}$ showed modified endothelial cells, and the intima was formed by foam macrophages and hypertrophic smooth muscle cells, without cholesterol crystals (Figure 5). There was elastic lamina disruption and smooth muscle cell hyperplasia, which are both characteristics of homocysteineinduced lesions. Comparing intimal thickening among the groups showed a pronounced intimal hyperplasia in group $\mathrm{C}$ as compared to group $\mathrm{M}$, with a significant difference between groups $(p=0.0041)$. Results are shown in table 1 .

\section{Biochemical analysis}

Total cholesterol, HDL and triglyceride levels in plasma were analyzed, and no significant difference was observed between the two groups, which suggested that they had no

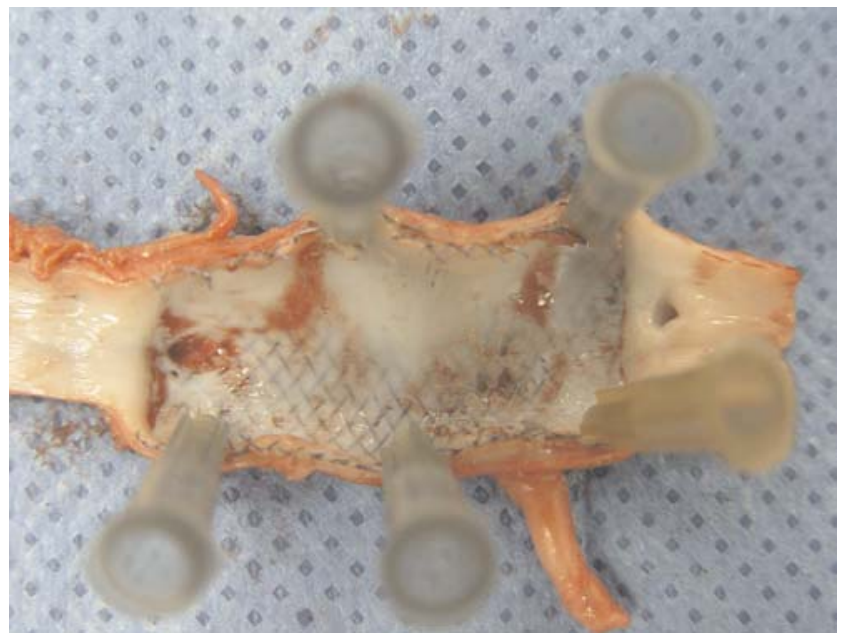

Figure 2 - Macroscopic view of stent in pig aorta in Group C

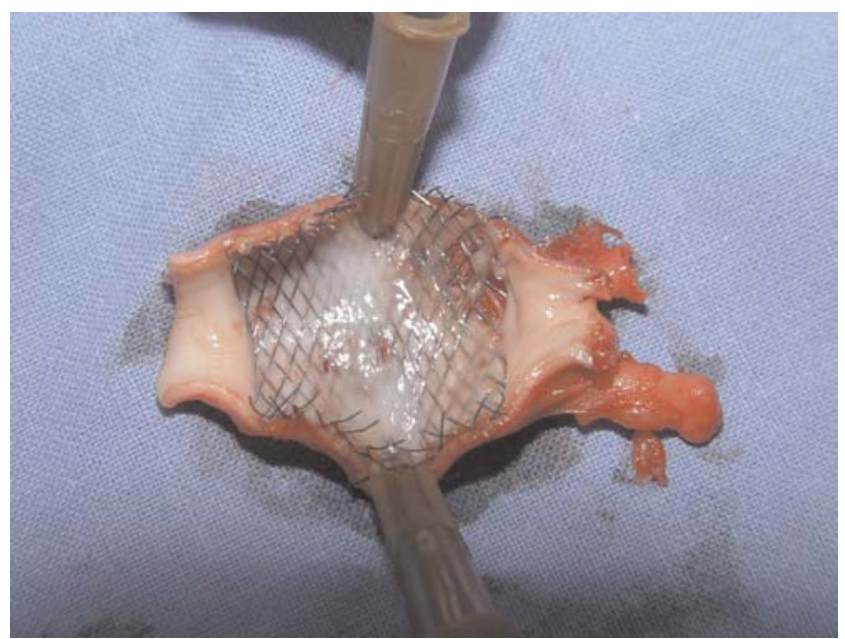

Figure 3 - Macroscopic view of stent in pig aorta in Group M influence on the final results (results are show in tables 2, 3 and 4).

Normal plasma homocysteine levels for animal experiments have not been established. We considered the average plasma homocysteine levels in Group $\mathrm{C}$ to be normal, and we compared plasma homocysteine levels in Group $\mathrm{M}$ to Group C. In Group C, there was no change in homocysteine levels during the eight-week-study (average values: 14.40 $\mu \mathrm{mol} / \mathrm{l}$ on day $0 ; 16.73 \mu \mathrm{mol} / \mathrm{l}$ on day $30 ; 16.47 \mu \mathrm{mol} / \mathrm{l}$ on day 60 ). In group $M$, the average value for plasma homocysteine levels was $17.47 \mu \mathrm{mol} / \mathrm{l}$ on day $0,59.80 \mu \mathrm{mol} / \mathrm{l}$ on day 30 , and $32.74 \mu \mathrm{mol} / \mathrm{l}$ on day 60 (table 5). Thus, plasma homocysteine in Group $\mathrm{M}$ reached a level approximately

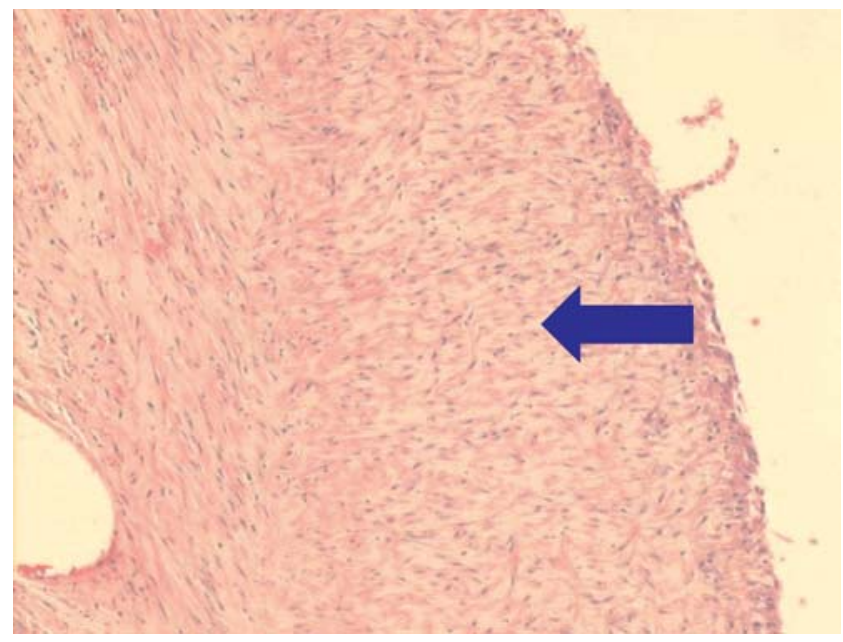

Figure 4 - Histological evaluation of aortas in Group C. The intima was thick, showing no endothelial deposits, a well-defined internal elastic lamina and a lack of inflammatory cells (blue arrow)

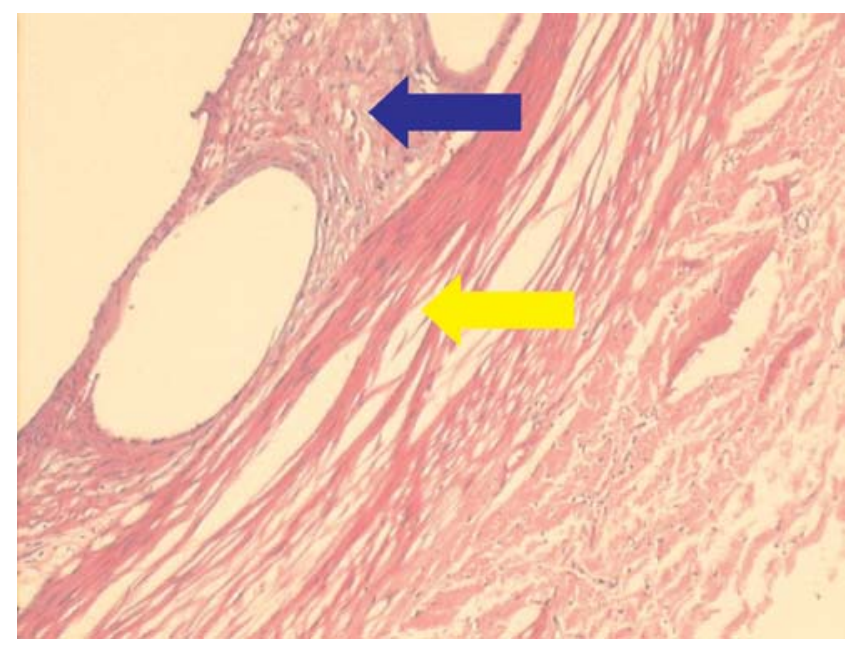

Figure 5 - Histological evaluation of aortas in Group M. Modified endothelial cells, with foam macrophages (blue arrow), were present in all specimens. No smooth muscle cells, cholesterol crystals or inflammatory cells were observed at the intima. There was elastic lamina disruption (yellow arrow) and smooth muscle cell hyperplasia, which are both characteristics of homocysteine-induced lesions 
Table 1 - Intimal thickening statistical analysis

\begin{tabular}{|c|c|c|c|c|c|c|c|c|}
\hline Group & $\mathrm{n}$ & Median & Interquartil range & Min & Max & Average & Standard deviation & $p$ \\
\hline Control & 7 & 467,05 & 422,478 & 345,644 & 816,288 & 545,1983 & 202,4074 & 0,0041 \\
\hline Methinine & 7 & 269,32 & 154,41 & 131,316 & 383,154 & 268,7414 & 86,6294 & \\
\hline
\end{tabular}

Table 2 - Total cholesterol levels (mg/dl)

\begin{tabular}{|c|c|c|c|c|c|c|c|c|}
\hline Time & Group & Median & Interquartíl range & Min & Máx & Average & Standard deviation & $p$ \\
\hline \multirow[t]{2}{*}{0 day } & Control & 86 & 13 & 71 & 92 & 82,57 & 7,66 & 0,9015 \\
\hline & methinine & 85 & 6 & 63 & 111 & 85,86 & 14,01 & \\
\hline \multirow[t]{2}{*}{30 days } & Control & 85 & 31 & 71 & 120 & 90,57 & 17,92 & 0,6200 \\
\hline & methionine & 92 & 42 & 49 & 101 & 80,57 & 22,23 & \\
\hline \multirow[t]{2}{*}{60 days } & Control & 106 & 22 & 78 & 122 & 103,57 & 14,76 & 0,3829 \\
\hline & methionine & 92 & 24 & 70 & 125 & 96,14 & 17,58 & \\
\hline
\end{tabular}

Table 3 - HDL levels (mg/dl)

\begin{tabular}{|c|c|c|c|c|c|c|c|c|}
\hline time & Group & Median & Interquartil range & Mín & Máx & average & Standard deviation & $p$ \\
\hline \multirow[t]{2}{*}{0 day } & Control & 38 & 5 & 31 & 45 & 37,71 & 4,54 & 0,0530 \\
\hline & methionine & 42 & 4 & 39 & 48 & 42,57 & 2,94 & \\
\hline \multirow[t]{2}{*}{30 days } & Control & 42 & 8 & 35 & 52 & 42,29 & 5,56 & 1 \\
\hline & methionine & 48 & 24 & 21 & 52 & 40,00 & 12,94 & \\
\hline \multirow[t]{2}{*}{60 days } & Control & 48 & 17 & 32 & 57 & 45,57 & 9,36 & 0,2593 \\
\hline & methionine & 39 & 9 & 33 & 46 & 40,43 & 5,00 & \\
\hline
\end{tabular}

Table 4 - Plasma triglyceride levels (mg/dl)

\begin{tabular}{|c|c|c|c|c|c|c|c|c|}
\hline time & Group & Median & Interquartíl range & Mín & Máx & average & Standard deviation & $p$ \\
\hline \multirow[t]{2}{*}{0 day } & Control & 26 & 10 & 22 & 34 & 27,57 & 4,79 & 0,2086 \\
\hline & Methionine & 33 & 15 & 21 & 45 & 33,71 & 8,48 & \\
\hline \multirow[t]{2}{*}{30 days } & Control & 33 & 29 & 25 & 62 & 38,00 & 14,85 & 0,1282 \\
\hline & Methionine & 57 & 68 & 19 & 118 & 62,29 & 36,65 & \\
\hline \multirow[t]{2}{*}{60 days } & Control & 33 & 25 & 19 & 75 & 40,00 & 18,77 & 0,0973 \\
\hline & methionine & 20 & 21 & 11 & 60 & 25,29 & 17,12 & \\
\hline
\end{tabular}

Table 5 - Plasma homocysteine levels ( $\mu$ mol/l)

\begin{tabular}{|c|c|c|c|c|c|c|c|c|}
\hline time & Group & Median & Interquartíl range & Mín & Máx & average & Standard deviation & $p$ \\
\hline \multirow[t]{2}{*}{0 day } & Control & 13,1 & 3,2 & 12 & 20 & 14,40 & 2,79 & 0,3829 \\
\hline & methionine & 16,4 & 10,1 & 10 & 28 & 17,47 & 6,14 & \\
\hline \multirow[t]{2}{*}{30 days } & Control & 16,1 & 5,4 & 13 & 24,2 & 16,73 & 3,88 & 0,0006 \\
\hline & Methionine & 56,7 & 13,7 & 45 & 84,1 & 59,80 & 12,64 & \\
\hline \multirow[t]{2}{*}{60 days } & Control & 16,2 & 3,3 & 12,3 & 24,5 & 16,47 & 3,98 & 0,2086 \\
\hline & methionine & 29,3 & 36,1 & 13 & 54,7 & 32,74 & 18,48 & \\
\hline
\end{tabular}


three times higher than Group C during the 30-day period before surgery. Although significant hyperhomocysteinemia ( $p=0.0006)$ was detectable after 1 month in group $\mathrm{M}$, the levels of homocysteine stabilized after two months in both groups.

\section{DISCUSSION}

In the present study, the pig model was selected for two main reasons. First, swine models can be easily manipulated to mimic human vascular disease by atherogenic diets, and they display a remarkable similarity in lesion distribution, pathogenesis and morphology with those of humans. ${ }^{12}$ The pig's arterial system is prone to hypercoagulability, and their fibrinolytic system is not as active as the canine model. The coagulation system may be a relevant factor in neointimal hyperplasia and restenosis after balloon dilation and stent placement. ${ }^{2,12}$ Second, experiments with sulfur amino acid metabolism in this species more closely resemble the results obtained in humans. Additionally, it has previously been demonstrated that pigs fed with a methionine-rich diet for 30 days develop hyperhomocysteinemia, thrombotic events, and arterial lesions similar to those in patients with homocystinuria. ${ }^{13}$

The plasma homocysteine concentrations recorded in our study ranged from 17.47 to $59.80 \mu \mathrm{mol} / \mathrm{L}$, which are of similar levels to those observed in patients with hyperhomocysteinemia and are thought to contribute to premature vascular disease. ${ }^{7-9,18}$ In addition, hyperhomocysteinemia developed in animals without significant changes in the serum lipid profile, which suggests that there was no interference from hypercholesterolemia. Our findings reproduce the situation encountered in young homocysteinemic patients, whose serum lipid profiles usually do not reveal hypercholesterolemia and in whom artherosclerotic lesions contain little or no evidence of accumulated lipid cores. The present study results in experimental hyperhomocysteinemic pigs are in accordance with the conclusions that homocysteinemia could represent a nonlipid model for artherosclerosis initiation.

With respect to homocysteine toxicity against vascular cells, it is possible that priming vascular cells with homocysteine results in the release of cytokines and/or growth factors by injured cells, as is the case after balloon-induced vascular injury. Specifically, smooth muscle cell activation and replication in the media may be driven by basic fibroblast growth factor released by injured medial cells, although other unknown growth factors may also be involved. The similarities between homocysteine and balloon injuryinduced vascular wall alterations will serve as a framework for a working hypothesis to elucidate the mechanisms that account for the vascular consequences of hyperhomo- cysteinemia. ${ }^{13} 19,24$

A pig's abdominal aorta has positive features that make it suitable for experimentation, such as size and high flow. The pig aortas used in our experiment were, on average, 8 $\mathrm{mm}$ in diameter. There are advantages in handling a vessel of such diameter when implanting stents because arteries with a high flow are less likely to present with thrombosis, whereas stents implanted in low flow arteries are more prone to intimal hyperplasia. ${ }^{25}$

Although stents may prevent elastic retraction by means of positive geometric remodeling, they are not immune to causing harm to the vascular system. Stents can be related to thrombus formation, higher inflammatory reaction, and neointimal thickening because the endothelial lesion exposes the subintimal elements, resulting in a cicatricial answer to injury. ${ }^{1}$ The reason we chose nitinol stents is related to their good biocompatibility, with minimal thrombus deposition or inflammatory response. ${ }^{2}$

There are some differences between self-expanding and balloon-expanded stents, and their specific properties may affect the outcomes of experimental research. Mangell studied stent/vessel interaction and distensibility following the natural increase in vascular diameter using self-expanding and balloon-expanded stents in a swine model and concluded that balloon-expanded stents have no pulsatile movement and may detach when the vessel diameter increases. ${ }^{14}$ Harnek found that insertion of a self-expandable nitinol stent without previous PTA results in less intimal hyperplasia than if PTA is performed prior to stenting; this suggests that direct stenting can be used in angioplasty sessions with a favorable outcome. ${ }^{16}$ Sullivan found that maintaining an intact internal elastic lamina is an important factor for prevention of intimal hyperplasia and restenosis in stented iliac arteries. ${ }^{17}$ Based on these results; we chose to implant self-expanding stent without previous PTA in our study.

Intimal hyperplasia is the key point in this study. Schwartz states that the phases of neointimal formation in the pig may be similar to humans..$^{25,26}$ The major limitation of animal models is the lack of pre-existing disease in the vascular wall, like atherosclerosis in humans. ${ }^{11}$ However, the findings related to intimal hyperplasia after stent implantation in experimental animals maintained on an atherogenic diet were not different when comparing normal and stenotic arteries. ${ }^{11,25,26}$ Obtaining histological slices four weeks after stents were added seems to be sufficient for intimal thickening studies. In the pig model, the reaction to a lesion led to the formation of neointimal hyperplasia in one or two weeks and the process was complete within twenty-eight days. In terms of histology, size, and cellular density, this process is similar to what occurs in humans..$^{1,411-14}$ After implanting stents in the iliac and carotid arteries of pigs, Verheye et al. 
conducted histological studies one to six months after implantation and stated that the vascular wall was completely covered by endothelial-type cells within one month. ${ }^{27}$ Similar to these authors, we studied intimal thickening of the vessel wall 30 days after stent implantation to analyze arterial wall alterations. Smet et al. studied the amount of neointima found after stent placement in pre-existent plaque mass in the peripheral arteries of micropigs. Plaque formation was achieved after exposure to diet-induced atherosclerosis. They concluded that the amount of plaque present before stent placement was a determinant of the amount of intimal hyperplasia present after stent placement. ${ }^{15}$ In contrast, existing lesions caused by hyperhomocysteinemia did not enhance intimal hyperplasia in the present study.

The relationship between hyperhomocysteinemia and restenosis after peripheral vascular intervention remains controversial; some studies have attempted to elucidate several potential mechanisms by which hyperhomocysteinemia may stimulate myointimal hyperplasia. ${ }^{19,23,24}$ Laxdal et al. investigated the relationship between plasma homocysteine and other haemostatic variables, and restenosis or reocclusion after endovascular treatment of symptomatic atherosclerosis of the femoropopliteal artery above the knee. In these studies, they found that plasma homocysteine did not appear to influence endovascular intervention outcomes. ${ }^{22}$ After comparing the morphology of the muscular femoral artery in atherosclerosis and hyperhomocysteinemic patients to atherosclerotic vessels from normal homocysteine level patients, Vermeulen et al. concluded that hyperhomocysteinemia is associated with a significant decrease in the smooth muscle cell/extracellular matrix ratio of the medial layer of the muscular femoral arteries, without significant changes in medial thickness. ${ }^{23}$ On the other hand, the effects of elevated plasma homocysteine responses in the peripheral vascular bed, after stent placement, have not been reported. In our study, aside from preexisting lesions caused by hyperhomocysteinemia, no significant intimal hyperplasia was observed. This was an unexpected result, and we believe that some therapeutic effects of homocysteine on restenosis after stent deployment will be elucidated with further research. This is the first report of a hyperhomocysteinemia and intimal hyperplasia experimental model after stent placement in pig aortas. We can only speculate on our findings; perhaps, as Vermeulen et al. concluded, a mechanism exists that lowers the smooth muscle cell/extracellular matrix ratio. Further studies are required to better understand these findings.

\section{CONCLUSION}

Insertion of self-expandable nitinol stent in pig aortas after 30 days on a methionine-rich diet results in less intimal hyperplasia than is found in normal pigs.

\section{ACKNOWLEDGMENTS}

This research was supported by CNPq, Fundo de Incentivo à Pesquisa of Hospital de Clínicas de Porto alegre, and Post-Graduate Program os Surgery, UFRGS.

\section{REFERENCES}

1. Dolmatch BL. Healing response to vascular stent-grafts. J Vasc Surg. 2000;31:1285-89.

2. Palmaz JC; Bailey, S; Marton, D; Sprague, E. Influence of stent design and material composition on procedure outcome. J Vasc Surg. 2002;36:1031-9.

3. Palmaz JC, Sibbitt R, Reuter S, Tio FO, Rice WJ. Expandable intraluminal graft: preliminary study. Work in progress. Radiology 1985; 156:73-7.

4. Post MJ, Borst C, Kuntz RE. The relative importance of arterial remodeling compared with intimal hyperplasia in lumen renarrowing after balloon angioplasty: a study in the normal rabbit and hypercholesterolemic Yucatan minipig. Circulation. 1994;89:2816-21.

5. Levy D, Kannel WB. Cardiovascular risks: new insights from Framingham. Am Heart J. 1988;116:266-72.

6. Libby P, Ridker P, Maseri A. Inflammation and atherosclerosis. Circulation. 2002;105:1135-43.

7. Nehler MR, Taylor Jr. LM. Homocysteinemia as a risk factor for atherosclerosis: a review. Cardiovasc Surg. 1997;5:559-67.
8. Taylor LM, Moneta G, Sexton GJ, Schuff RA, Porter JM. Prospective blinded study of the relationship between plasma homocysteine and progression of symptomatic peripheral arterial disease. J Vasc Surg. 1999;29:8-21.

9. Venâncio LS, Burini RC, Yoshida WB. Hiper-homocisteinemia na doença arterial periférica. J Vasc Bras. 2004;3:31-7.

10. Simoni G, Galleano R, Ceppa P, Desalvo P, Cariati P, Baccini P, et al. Prevention of vascular intimal hyperplasia in small caliber prosthesis. Minerva Cardioangiol. 1995;43:205-9.

11. Wolf YG, Gertz D, Banai S. Animal models in syndromes of accelerated arteriosclerosis. Ann Vasc Surg. 1999;13:328-38.

12. Ratcliffe HL, Luginbuhl H. The domestic pig: a model for experimental atherosclerosis. Atherosclerosis. 1971;13:133-6.

13. Rolland PH, Friggi A, Barlatier A, Piquet P, Latrille V, Faye MM, et al. Hyperhomocysteinemia-induced vascular damage in the minipig. Captopril - hydrochlorothiazide combination prevents elastic alterations. Circulation. 1995;91:1161-74. 
14. Mangell P, Malina M, Vogt K, Lindh M, Schroeder T, Risberg B, et al. Are self-expanding stents superior to balloon-expanded in dilating aortas? An experimental study in pigs. Eur J Vasc Endovasc Surg. 1996;12:287-94.

15. de Smet BJ, Kuntz RE, van der Helm YJ, Pasterkamp G, Borst C, Post MJ. Relationship between plaque mass and neointimal hyperplasia after stent placement in Yucatan micropigs. Radiology. 1997;203:484-8.

16. Harnek J, Zoucas E, Stenram U, Cwikiel W. Insertion of self-expandable nitinol stents without previous ballon angioplasty reduces restenosis compared with PTA prior to stenting. Cardiovasc Interv Radiol. 2002;25:430-6.

17. Sullivan TM, Ainsworh SD, Langan EM, Taylor S, Snyder B, Cull D, et al. Effect of endovascular stent strut geometry on vascular injury, myointimal hyperplasia and restenosis. J Vasc Surg. 2002;36:143-9.

18. McCully KS, Wilson RB. Homocysteine theory of arteriosclerosis. Atherosclerosis. 1975;22:215-27.

19. McCully KS. Homocysteine and vascular disease. Nature Medicine. 1996;2:386-9.

20. Stahlke Jr. HJ, França LHG, Stahlke PH, Stahlke PS. Hiperhomocisteinemia causando aterogênese na aorta de coelhos - modelo experimental. J Vasc Brás. 2004;3:20-30.

21. França LHG, Pereira AH, Perini SC, Aveline CC, Argenta R, Mollerke $\mathrm{RO}$, et al. Aterogênese em artéria ilíaca comum de suínos submetidos à homocisteinemia induzida pela ingesta de metionina. J Vasc Bras. 2006;5:11-6.
22. Laxdal E, Eide GE, Wirsching J, Jenssen GL, Jonung T, Pedersen G, et al. Homocysteine levels, haemostatic risk factors and patency rates after endovascular treatment of the above-knee femoro-popliteal artery. Eur J Vasc Endovasc Surg. 2004;28:410-7.

23. Vermeulen EGJ, Niessen HWJ, Bogels M, Stehouwer CD, Rauwerda JA, vanHinsbergh VW. Decreased smooth muscle cell/extracellular matriz ratio of media of femoral artery in patients with atherosclerosis and hyperhomocysteinemia. Arterioscler Thromb Vasc Biol. 2001;21:573-7.

24. Woo KS, Chook P, Lolin YI, Cheung AS, Chan LT, Sun YY, et al. Hyperhomocyst(e)inemia is a risk factor for arterial endothelial dysfunction in humans. Circulation. 1997;96:2542-4.

25. Richter GM, Palmaz JC, Noeldge G, Tio F. Relationship between blood flow, thrombus, and neointima in stents. J Vasc Interv Radiol. 1999;10:598-604.

26. Schwartz RS. The vessel wall reaction in restenosis. Semin Interv Cardiol. 1997;2:83-8.

27. Schwartz RS. Pathophysiology of restenosis: interaction of thrombosis, hyperplasia and/or remodeling. Am J Cardiol. 1998;81:14E-17E.

28. Verheye S, Salame MY, Robinson KA, Post MJ, et al. Short and longterm histopathologic evaluation of stenting using a self-expanding nitinol stent in pig carotid and iliac arteries. Cathet Cardiovasc Intervent. 1999;48:316-23. 